\title{
2016 ACMG Annual Meeting presidential address: the practice of medical genetics: myths and realities
}

\author{
Gerald L. Feldman, MD, PhD ${ }^{1,2}$
}

I want to thank you for allowing me to serve as your President of the American College of Medical Genetics and Genomics, and it is my honor to serve as President for another year. What I say here is my own opinion and should not be taken as representing any official position of ACMG. I want to focus on the issues we deal with, but more importantly, how we address those issues, because that's what will determine the future of our specialty.

When putting together this address, I found it helpful to look at the titles of past presidential addresses. I found these fascinating-in some ways, they were ahead of their time, but in other ways, it was déjà vu all over again. For example, in the 2000 presidential address, Dr. Rod Howell identified key areas for ACMG to focus on: "creating and sustaining economic viability, educational activities at the state, federal, insurance industry and the general public, and improving communication with the membership." Sounds familiar.

Historically, medical genetics operated out of academic medicine departments; not all were physicians, most were internists (Figure 1). They dealt with monogenic disorders with biochemical, hematologic, or chromosomal etiologies. With the rise of dysmorphology and prenatal diagnosis, pediatric and OB/GYN departments became the preferred home. All physicians were board-certified in another specialty, so, despite the seriousness of their self-declared medical geneticist title, such self-declaration was not enough to confer legitimacy. In the 1980s, the American Board of Medical Genetics was formed, training programs were accredited, and board certification was implemented. In 1991, medical genetics became the 24th primary specialty board to be admitted into the American Board of Medical Specialties. Although ABMG was allowed to accredit training programs for medical geneticists who were not physicians, it was prohibited from doing the same for master's degree-level genetic counselors. Fast forward to today.

Myth: ACMG has done nothing in the areas that concern me the most.

Reality: The ACMG is the major organization effecting change for clinical geneticists and laboratory geneticists.
Here are just a few examples of what ACMG has done during the past year:

- ACMG has published a revised Scope of Practice, a revised Direct to Consumer Testing statement, and a new Clinical Utility Policy Statement, and has collaborated with other organizations on key issues in FDA/ Laboratory-Developed Test regulations.

- Improved communication with our membership through social media and other forms of communication.

Myth: Being a geneticist is financially disheartening and that's why medical students don't enter the field.

Reality: This is an urban legend that we need to extinguish.

While geneticist salaries are not as high as those of some specialists, they are not that different from those of other pediatric specialties. $^{2}$ The 2016 ACMG Salary Survey results document very competitive starting salaries, but, for those already in practice, geneticists are not being compensated comparably. ${ }^{3}$ That's what needs to be fixed, not the starting salaries. For my recent graduating residents, the salary offers ranged from $\$ 130,000$ to $\$ 185,000$, with an average of $\sim \$ 160,000$, with many offering additional incentives. As these newer trainees move up in the ranks, I hope their salaries will increase appropriately. It's important to be proactive and support each other in this process.

Myth: We have a great system in our clinic, but genetics patients are complicated. There's no way I can see patients in less time.

Reality: That model is not sustainable! And we better figure out how, which leads me to the next myth.

Myth: Poor reimbursement for clinical services is the root of our problems.

Reality: This is correct, but the root is our clinical practice model, which reimburses us poorly for the time spent with each patient. We cannot survive on clinical income alone in the current practice model.

${ }^{1}$ Center for Molecular Medicine and Genetics, Department of Pediatrics, Wayne State University, Detroit, Michigan, USA; ${ }^{2}$ Center for Molecular Medicine and Genetics, Department of Pathology, Wayne State University, Detroit, Michigan, USA. Correspondence: Gerald L Feldman (gfeldman@med.wayne.edu)

The ACMG presidential address was presented 9 March 2016 at the 2016 Annual Meeting of the American College of Medical Genetics and Genomics, Tampa, Florida. 


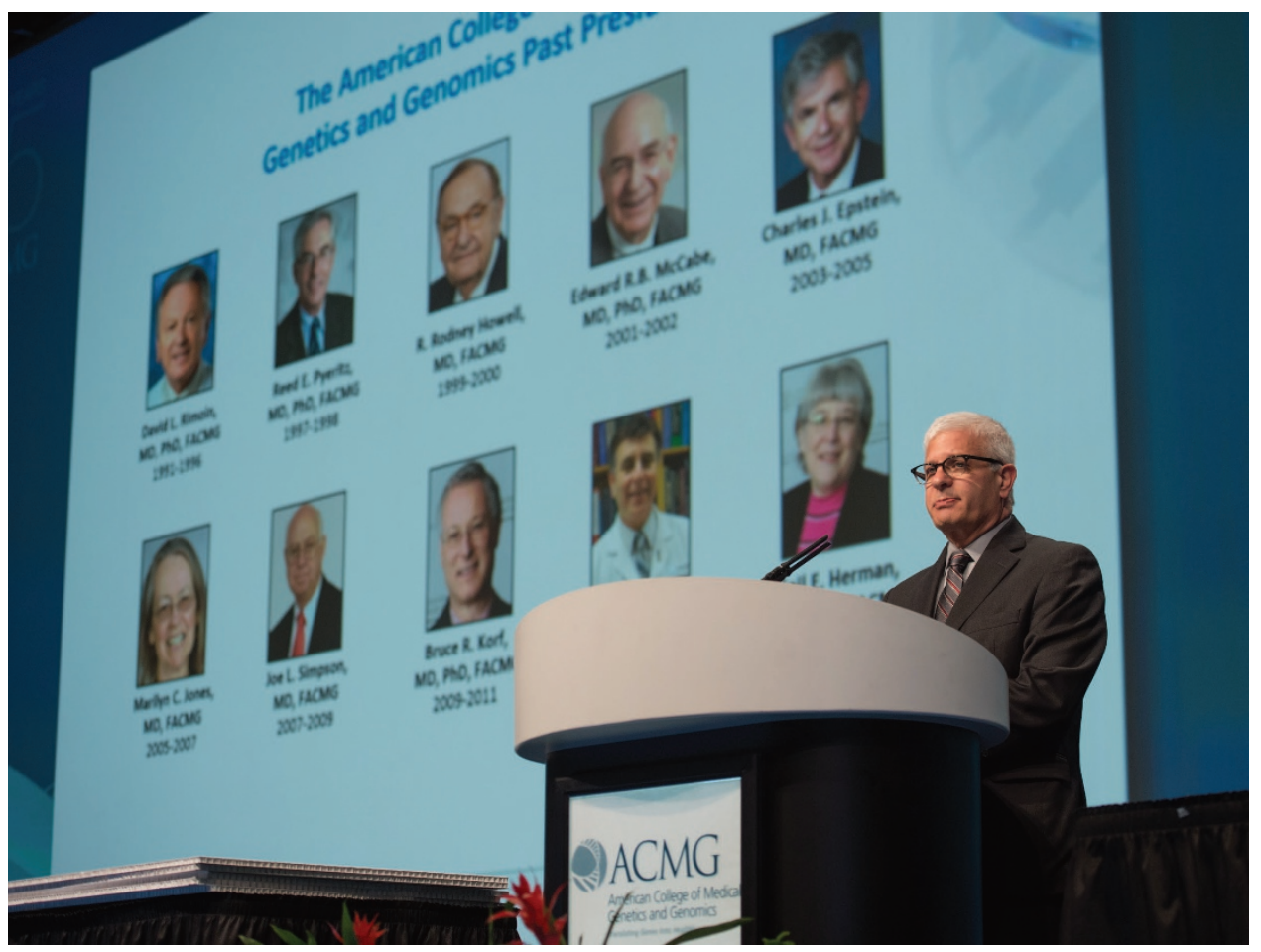

Figure 1 Dr. Gerald Feldman, FACMG and current ACMG President, honored ACMG's past presidents during the Presidential Plenary session as part of the College's 25th Anniversary Celebratio".

Many surveys of clinical geneticists document the same conclusion: clinical geneticists spend too much time per patient (up to 7 hours on a new patient and 3.5 hours on a return patient) and a large amount of time on nonreimbursable patient-related activities; few thought they could increase that number. ${ }^{4,5}$ I respectfully disagree. As genetic testing becomes more complex, the solution is in our hands and it requires new practice models.

Myth: Genetic counselors love their jobs in academic medicine and will not leave the clinical world or the corollary, there are enough genetic counselors to replace those who leave.

Reality: An adequate work force is a major issue. At the current time, there aren't enough genetic counselors to fill the available positions and there won't be for the near future.

Our clinic models are no longer sustainable. One recent approach is the addition of a "genetics assistant" to perform many of the nonbillable responsibilities and thus free counselor and physician time to see additional patients. Genetic counselor-only patients with appropriate MD supervision is another way to increase efficiency and the number of patients seen.

Myth: Laboratory reimbursement for genetic testing is not profitable; soon, there will be only a few large commercial labs left.

Reality: This might be true unless we do something about it. This is a complicated discussion, well beyond this presentation. However, there are a few key points.
1. There are increasing requirements for clinical laboratories to provide specific technical information on test procedures and value/performance, including demonstrating clinical utility.

2. Reimbursement for interpretation by a $\mathrm{PhD}$ laboratory geneticist is even more complicated and likely will require an act of Congress.

3. ACMG is involved at many levels, including collaborations with other organizations.

Myth: Our workforce is old and decrepit.

Reality: In the last three board exam cycles, we have certified 268 new clinical geneticists, 57 clinical biochemical geneticists, 49 medical biochemical geneticists, 213 clinical molecular geneticists, and 115 clinical cytogeneticists. While there may not be enough board-certified geneticists, the number of new graduates has been stable.

The problem is that not enough trainees are entering residency programs to fill all available residency slots. Only $\sim 50 \%$ of available funded medical genetics slots in the US are filled. If a qualified applicant wants to specialize in medical genetics, there are opportunities. For the categorical medical genetics residency, the numbers of programs, positions, and applicants have been stable, not increasing. We created this problem, so we need to fix it. Initially, for the categorical residency, at least 2 years in another primary specialty was a prerequisite. But why? I believe that most geneticists at the time did not feel that "geneticists" could train other "physicians" in medicine, perhaps because we came from 
so many different backgrounds and the practice of medical genetics varied from place to place. Recently, that requirement was changed to only 1 year, but only a few programs have embraced that option. My recommendation is to create a categorical match directly from medical school-a 3-year medical genetics residency that includes a 1-year built-in transitional year. I am certain that would increase the number of applicants. For combined pediatrics-medical genetics training programs, the required years of training were recently decreased from 5 to 4 years. As a result, the number of applicants has doubled, the number of filled positions has almost tripled, and the number of US graduates has increased. While there was some opposition, the alternative was to do nothing while medical genetics and genomics wilted and died. Clinical geneticists are in demand-let us think creatively to increase the number of trainees.

ACMG and ACMGF are also actively involved in increasing the number of trainees, including support for the Summer Scholars Fellowship program, which funds 20-30 second-year medical students for exposure to medical genetics. Already, some of these students have entered into medical genetics residency programs. There are clinical and research fellowship training opportunities through Genzyme, Pfizer, Horizon Pharma, and Shire. These are great opportunities to help ourselves.

In summary, we must decrease losses by using new models, such as genetic assistants. We must develop mechanisms for genetic counselors to independently see and bill for follow-up patients under the guidance of a physician. We must balance unfunded research and educational activities with patient care and decrease nonbillable time. We must increase revenuesusing telemedicine (if reimbursable), sharing costs for multidisciplinary clinics, and sharing in utilization management savings if involved. We must develop new residency training models.

Another idea is to create an "executive war college" for medical genetics and genomics similar to a pathology conference called "Executive War College: Conference on Laboratory and Pathology Management." Our conference would focus on the business of medical genetics and genomics, developing ideas for reshaping lab management, billing and reimbursement, and improving clinic efficiency.

So, what is our future? While we will never be a large specialty, we must start by acting like the medical specialty that we areby first obtaining hospital privileges as medical geneticists, not through another specialty. Second, it's the patient volume that keeps other specialties profitable along with demonstrating value. We must develop new practice models. We must ensure that genetic counselors and $\mathrm{PhD}$ laboratory geneticists become recognized providers. Our future is bright and sustainable; the keys are the new genetic/genomic tests and the amount of bioinformatics being generated. No other specialty is on the cutting edge of all aspects of medicine as we are. No other specialty understands genetics as we do. But nobody is going to do it for us-the time is now.

\section{DISCLOSURE}

The author is the medical director of a molecular genetics laboratory that performs clinical genetic testing.

\section{REFERENCES}

1. Howell RA. Some major milestones and future directions. ACMG Presidential Address. Genet Med 2000; 2:255-258.

2. American College of Medical Genetics and Genomics. ACMG 2015 Salary Survey Report, personal communication.

3. American Academy of Pediatrics. The Future of Pediatric Education II: A Project of the Pediatric Community: Clinical Genetics. https://www.aap.org/ en-us/about-the-aap/departments-and-divisions/department-of-education/ Documents/FOPE\%20I1\%20Genetics\%20Summary.pdf.

4. Cooksey JA, Forte G, Flanagan PA, Benkendorf J, Blitzer MG. The medical genetics workforce: an analysis of clinical geneticist subgroups. Genet Med 2006;8:603-614.

5. McPherson E, Zaleski C, Benishek K, et al. Clinical genetics provider real-time workflow study. Genet Med 2008;10:699-706. 